九州大学学術情報リポジトリ

Kyushu University Institutional Repository

\title{
STRUCTURE FORMATION OF SCIENTIFIC BRAINWARE AS A BASIS OF DATA BASE MANAGEMENT
}

Kitagawa, Toshio

Director of International Institute for Advanced Study of Social Information Science | Honorary Professor of Kyushu University

https://doi.org/10.5109/13114

出版情報：統計数理研究. 17 (3/4)，pp.55-64，1977-03. Research Association of Statistical Sciences

バージョン：

権利関係 : 


\title{
STRUCTURE FORMATION OF SCIENTIFIC BRAINWARE AS A BASIS OF DATA BASE MANAGEMENT*
}

\author{
By \\ Tosio Kitagawa** \\ (Received August 1, 1976)
}

\section{Introduction}

Since the birth of computer science and technology, there has passed about a quarter of a century during which a firm common recognition of two notions called hardware and software has been established both among academic and social communities. In view of the recent advancements of the computer technologies, the author [1] has introduced a new notion of brainware in connection with intelligent and integrated information system, which has been reflecting the needs and the feasibility of computer network system with distributed data bases. The purpose of the present paper is to discuss a formation process of brainware in the area of scientific researches and developments. A broad classification of sciences into three classes, called (i) discipline-oriented, (ii) mission-oriented, and (iii) assessment-oriented ones, is introduced for this purpose. An analysis of research subprocesses with the specific reference to their information processing aspects is also indispensable for our present purpose. The method which we shall adopt in this paper is based upon the author views on the logics of information science being represented by three coordinate systems in his papers [2], [3], [4].

In Section 2 the logical aspects of a science are analysed from the standpoint of informative logics, and we shall make clear the conditions for a science to be a system of informations. In Section 3 we shall first discuss the notion of brainware in connection with integrated and intelligent system of information, and then we shall proceed to introduce scientific brainware, that is, brainware to be associated with a science. Section 4 is devoted to discussions of the usages of artificial intelligence in scientific researches. Section 5 is concerned with the formation procedures of scientific brainware regarding its function, its structure, and its teasibility. Our specific references are given in connection with logic of information science.

* This work was done as a member of the Research Unit “ $\mathrm{B}-1$ : Consolidated Research on Formation Process of Scientific Information System" belonging to the Special Research Project "Formation Process of Information System and Organization of Scientific Informations" supported by the Research Grant of the Ministry of Education of Japan.

** Honorary Professor of Kyushu University, Director of International Institute for Advanced Study of Social Information Science. 


\section{Science as a system of informations in view of the informative logics.}

A mere accumulation of informations is to be distinguished with a science. A science should be rather considered as a system of informations in view of the informative logics which we have introduced in a series of our papers [2], [3], [4] and [5]. Since the present paper is heavily referring to the basic notions introduced in the informative logics explained in these papers, it will be convenient to give three coordinate systems of informative logics in the following Table 1.

Table 1. Three coordinate systems in informative logics

\begin{tabular}{|c|c|c|c|}
\hline (I) \& (II) (III) & $\left(\mathrm{III}_{1}\right)$ Control & $\left(\mathrm{III}_{2}\right)$ Eizon & $\left(\mathrm{III}_{3}\right)$ Creation \\
\hline $\begin{array}{ll}\left(\mathrm{I}_{1}\right) & \text { (a) Objectivity } \\
\left(\mathrm{I}_{2}\right) & \text { (b) Subjectivity } \\
\left(\mathrm{I}_{3}\right) & \text { (c) Practice }\end{array}$ & $\begin{array}{l}\left(a_{1}\right) \text { Pattern } \\
\left(b_{1}\right) \text { Operation } \\
\left(c_{1}\right) \text { Optimization }\end{array}$ & $\begin{array}{l}\left(\mathrm{a}_{2}\right) \text { Chaos } \\
\left(\mathrm{b}_{2}\right) \text { Adaptation } \\
\left(\mathrm{c}_{2}\right) \text { Self-conservation* }\end{array}$ & $\begin{array}{l}\left(a_{3}\right) \text { Transformation } \\
\left(b_{3}\right) \text { Strategy } \\
\left(c_{3}\right) \text { Communication** }\end{array}$ \\
\hline $\begin{array}{l}\left(\mathrm{II}_{1}\right)(\alpha) \text { Cognition } \\
\left(\mathrm{II}_{2}\right)(\beta) \text { Direction } \\
\left(\mathrm{II}_{3}\right)(\gamma) \text { Evaluation }\end{array}$ & $\begin{array}{l}\left(\alpha_{1}\right) \text { Deduction } \\
\left(\beta_{1}\right) \text { Control } \\
\left(\gamma_{1}\right) \text { Efficiency }\end{array}$ & $\begin{array}{l}\left(\alpha_{2}\right) \text { Induction } \\
\left(\beta_{2}\right) \text { Eizon } \\
\left(\gamma_{2}\right) \text { Reliability }\end{array}$ & $\begin{array}{l}\left(\alpha_{3}\right) \text { Abduction } \\
\left(\beta_{3}\right) \text { Creation } \\
\left(\gamma_{3}\right) \text { Plasticity }\end{array}$ \\
\hline
\end{tabular}

Detailed discussions are given in our papers [2], [3] and [4]. It is noted that the original versions of $\left(c_{2}\right)$ and $\left(c_{3}\right)$ in these papers were formally $\left(c_{2}\right)$ stability and $\left(c_{3}\right)$ learning. We shall not enter any detailed illustration of Table 1, hoping that the reference will be done in our papers.

$\left[1^{\circ}\right.$ The cognitive functions of a science can be now analysed with regard to the three subspaces $\left(\mathrm{III}_{1}\right),\left(\mathrm{III}_{2}\right)$ and $\left(\mathrm{III}_{3}\right)$

$\left(1^{\circ}\right)$ The control aspects of a science can be observed from the requirement that a science should satisfy the structural condition that its theory should be deductive.

$\left(2^{\circ}\right)$ The eizon aspects of a science can be observed from the requirement that a science should satisfy the condition that it should not be contradictory to observational and/or experimental facts but should be adaptive to real world existences and phenomena.

$\left(3^{\circ}\right)$ The creation aspects of a science can be observed from the requirement that a science should satisfy the condition that it should be plastic by admitting any necessary reorganization of its deductive structures given by control aspects, if it be required.

$\left(\alpha_{1}\right)$ The deductive structure of a science can be represented by logical connection networks of informations underlying in its construction, where each individual information can be represented by a node and each deduction route is being represented by a chord. A formation of logical connection network of informations in a science in this sense is nothing but a pattern formation as an objectivity $\left(\mathrm{I}_{1}\right)$ in the first coordination, that is, an objective representation of the world in their specific concern. 
$\left(\alpha_{2}\right)$ The inductive aspects of a science can be represented by accumulation procedures of informations which are based upon acquisition, reduction, and evaluation processes dealing with input informations. The input informations have come from outside world, and, in principle, they may not be exactly coincident with any existing structure of a science, but they may involve a chaos and/or fuzziness in informative logics discussed in our paper [5].

$\left(\alpha_{3}\right)$ The abductive aspects of a science can be observed in transformations of an existing structure of a science into another one. The history of sciences provides us with a lot of actual examples in which revolutionary changes of old paradigms were involved so as to induce a new paradigm according to the cognitive procedure called abduction, which is essentially a formation of hypotheses to be tested.

$\left[2^{\circ}\right]$ A science is not a mere ensemble of informations, but it is currently understood as a structured storage of informations regarding the specific domain of scientific researches. Furthermore we have to proceed to assert that a science should be better understood as a system of informations so far as the following crucial conditions of a system are being satisfied:

(i) The cutting principle of a system is satisfied, because the set of informations in a science is characterized by a specific proper subset of the total information set, although there may be some fuzziness in its boundaries.

(ii) The principle of self-conservation of a system is satisfied, because the set of informations constituting a science is self-conservative in views of the following three conditions which a science should satisfies:

(a) Existence of basic minimal subset of informations which characterises an establishment of a science and which should be contained in the set of informations constituting the science at any stage of its development.

(b) Existence of preliminary input information processing procedures by which a certain sort of input informations adequate to be considered in a science is acquired, filtered, and reduced, if necessary.

(c) Existence of structure formation procedures by which any new comming input information having been processed in the preliminary input information processing procedures can contribute to supplement and/or can create structure formation of a science. Input information can only be stored in the set of informations associated with a science if and only if it is neither contradictory nor trivial to deduction routes associated with the science and to experimental or observational data having been stored in the science.

(iv) Existence of stabilization of structure formation procedures. The set of informations constituting a science is always subject to a chance of restructuring when a new input information is duly acquired but is found to be non-acceptable according to the existing structure of the science. The logical process of restructuring must be commenced by an abductive formation of a new hypothesis to be tested. So far as such a new hypothesis is presented and accepted without any change of the basic structural framework of the science, which consists of its basic information set and its basic constitutional structure, the set of informa- 
tions associated with the science is said to be structurally stable. In most of its development stages, a science has a certain feature of stabilization by which most of new hypotheses are being presented and accepted within the region of structural stability.

A science as a system is not eternal, although the storage of informations associated with it may become a monumental existence. A science as a system is essentially a historical existence for which the process of birth, growth, breakdown, and disintegration must be expected to realise necessarily and ultimately. In fact, when a science as a system becomes to be too rigid to accept any new duly acquired input information and looses the plasticity to admit any structurally stable restructuring, the science should be condemned to be disintegrated as a system.

\section{Scientific brainware}

We are now going to explain the notion of brainware in general and scientific brainware in particular, on the basis of our views and along the line of our assertions given in Section 2.

There are the five key properties of a brainware which read as follows:

PROPERTY 1. Brainware constitutes a system of informations based upon an information system in the sense that it is concerned with its applicabilities to communication, computation, and control purposes. Moreover the information system associated with a brainware should be intelligent and integrated in the sense that it should have the following properties 2-5.

PROPERTY 2. The information system associated with a brainware has a theoretical model which satisfies the following conditions:

$2-1$ ) it gives a world structure description.

$2-2$ ) it admits to some extent a logico-mathematical deduction procedure.

$2-3$ ) it is incompletely specified in the sense that it admits an introduction of hypothesis.

PROPERTY 3. The information system associated with a brainware corresponds to the real world from which we can acquire a set of data which can serve to specify the model provided by the brainware. This correspondence is called a realization of the model of the brainware.

Property 4.

$\left(1^{\circ}\right)$ A set of computer aided simulation experiments (CASE) is possible in connection with an information system associated with brainware.

$\left(2^{\circ}\right)$ A hypothesis can be introduced because of the incomplete specification of the model associated with information system of a brainware, and the hypothesis is subject to a procedure of testing hypothesis in view of the data which are given by a realization of the mode.

$\left(3^{\circ}\right)$ The testing hypothesis enunciated above is subject to a successive process of inferences and controls.

PROPERTY 5. The usages of an intormation system associated with a brainware 
are concerned with the following three aspects:

$5-1)$ system analysis,

5-2) system synthesis,

$5-3)$ system assessments.

Now let us introduce the following definition.

DEFINITION 1. A brainware is said to be associated with a science if its world structure description constitutes the structure of the science, and is called a scientific brainware. It is noted here again the distinctions between disciplineoriented sciences and mission-oriented sciences can be observed from the fact whether and how far the world structure descriptions are belonging to scientific disciplines which characterise a discipline-oriented science. In fact the world structure descriptions in mission-oriented science are more or less lattice structured as compared with that of discipline oriented one which is tree structured.

In our previous paper [1], we have explained in some details several key notions such as world structure description, computer aided simulation, and intelligent and integrated information system which are indispensable for establishing a brainware. We are not going to repeat any detail of our arguments given in [1], but we aim in this paper to give a different overlook of a scientific brainware with two different emphases. The first emphasis is placed upon the usages of artificial intelligence in scientific brainware, as will be given in Section 4 . The second emphasis is devoted to the analysis of structure formation process of scientific brainware, to which Section 5 is devoted.

\section{The usages of artificial intelligence in scientific brainware}

A world structure description associated with a scientific brainware has the essential properties of deductivity, computability and realisability, which secure the crucial conditions of applicability and feasibility of testing hypothesis procedures. In this connection we emphasise the three cognition aspects of scientific information: $\left(\alpha_{1}\right)$ deduction, which is concerned with logico-mathematical activities to deduce a set of consequences from a set of hypotheses in our study of model: $\left(\alpha_{2}\right)$ induction, which is essentially a logical process of testing hypothesis in investigation: $\left(\alpha_{3}\right)$ abduction, which is a logical process of formation of hypothesis in survey and/or in experiment. A science as a system of informations is judged as to its artificial intellegence aspect according to the extent how much and to the depth how far the system admits an application of artificial intelligence procedure in dealing with $\left(\alpha_{1}\right)$ deduction, $\left(\alpha_{2}\right)$ induction and, $\left(\alpha_{3}\right)$ abduction. Here by artificial intellignce we imply the usages of computer and information processing apparata in virtue of hardware and software, in order to realize information functions in general and three cognition functions, including $\left(\alpha_{1}\right)$ deduction, $\left(\alpha_{2}\right)$ induction, and $\left(\alpha_{3}\right)$ abduction in particular. The usages of artificail intelligence in formation process of intelligent and integrated information system in a science are concerned with each one of the five component processes of research process in the science, namely, (i) production of informations, (ii) processing of informations, 
(iii) structuring of informations, (iv) storages and retrievals of informations, and (v) circulations and usages of informations, and they can be effective as much as each of component processes admits the usages of information processing machinaries including computers for its objectively specified procedures. It is extremely important in principle as well as very urgent in practice to remark that the usages of artificial intelligence in scientific brainware formation can only become to be effectively feasible and comprehensive enough by realizing the three crucial principles belonging to control space of informative logics, namely $\left(1^{\circ}\right)$ specification, $\left(2^{\circ}\right)$ standardization and, $\left(3^{\circ}\right)$ automation. In fact these three crucial principles have been established in the area of statistical quality control in production of materials as shown in [6]. It is quite natural and logical that there will be estab. lished a set of several crucial principles which are valid in manufacturing three wares, hardware, software, and brainware. We may go further to assert that brainware engineering should be established in the comming days in correspondence with hardware engineering and software ones.

In the present state of documentation practices, the most fundamental methodologies based upon $\left(1^{\circ}\right)$ specification, $\left(2^{\circ}\right)$ standardization, and $\left(3^{\circ}\right)$ automation are not systematically applied, as can be observed from the fact that even a standard format in writing scientific papers has not been specified in most of scientific circles. It is to be noted that the present stage of scientific publications has made an information storage and retrieval system to be very complicated and extremely labourous for academic research workers to manage and to be embeded in their daily research works.

\section{Formation procedures of scientific brainware}

The purpose of this section is to discuss how to deal with the formation procedures of scientific brainware regarding its function, its structure, and its feasibility, in virtue of computer science technology and logic of information science. In order to introduce and to develope a brainware in a science, it is required that three fundamental principles, namely, (i) specification (ii) standardization and (iii) automation, associated with computer science approaches to system formation will be adopted in so much as they are feasible and effective. These three principles are more or less concerned with control aspects of information architecture, and they are sharply contrasted to eizon aspects and creation aspects which a science should have as we have explained in Section 2. The reasons why we emphasise control aspects of information architecture in brainware formation are due to the fact that, without emphasising (i) specification, (ii) standardization, and (iii) automation, no systematic realization of brainwares can be foreseen, and also due to the recognition that, in view of recent trends in developement of computer technology in hardware and software, we may be able to expect a realization of brainware in large scale and in sophisticated way, provided that a subtle application of these three principles in our field will have been effectively implemented.

Regrading a system approach to brainware formation, it is indispensable to 
recognize that brainware constitutes not a small system but a large system whose characteristic features were discussed in our paper [7].

\section{1. Function formation procedure of scientific brainware}

$(\alpha)$ Cognition In view of the cognition coordination consisting $\left(\alpha_{1}\right)$ deduction, $\left(\alpha_{2}\right)$ induction and $\left(\alpha_{3}\right)$ abduction in the logic of information science, scientific brainware should have these information functions regarding cognition, since our notion of brainware is essentially connected with intelligent and integrated in. formation system, as we have explained in Section 3.

What we have to discuss is just the rôles of these cognition aspects which should be embedded in the usages of scientific brainware. From this point of view, it will be very helpful to consider the details of each typical science where each one of these cognition functions, deduction, induction and abduction will play a predominant rôle. Thus we may choose as such a typical science (i) mathematics for deduction, (ii) statistics for induction and (iii) field science as abduction.

$(\beta)$ Direction With reference to the direction coordination consisting of $\left(\beta_{1}\right)$ control, $\left(\beta_{2}\right)$ eizon, and $\left(\beta_{3}\right)$ creation, the brainware in our terminology should aim to play all of these three direction functions with a certain allocation of weights according to the specific problems in front of us. The direction coordination becomes essential when we have to deal with mission-oriented sciences, which aim to solve a certain set of actual problems by means of system science approaches. In most of discipline-oriented sciences the direction functions of informations are not evident in their first appearances, because the primary rôle of the storage of informations in a discipline-oriented science is thought to contribte to a formation of pattern understanding in its scientific area. The rôles and the functions to be expected to assessment-oriented sciences are essentially based upon the abduction procedures of forming a set of new hypotheses, and hence the direction aspects of assessment-oriented sciences may be said to be due to $\left(\beta_{3}\right)$ creation.

$(\gamma)$ Evaluation With regard to the evaluation coordination consisting, or $\left(\gamma_{1}\right)$ efficiency, $\left(\gamma_{2}\right)$ reliability, and $\left(\gamma_{3}\right)$ plasticity, the brainware function can and should be subject to a careful consideration to these evaluation aspects. Thus a brainware should be efficiently organized with respect to several efficiency concepts. In any sense a brainware must be minimal and sufficient for each purpose of usages. A brainware must be reliable enough to tuckle with any possible disturbance and/ or any possible damage within a certain limit. A brainware must be also plastic enough to be structually stable under any possible changes of underlying theoretical models and experimental premises within a certain limit.

\section{2. Structure formation procedure of scientific brainware}

$\left(1^{\circ}\right)$ Correspondences among various objective descriptions

In view of the structure coordination consisting of (a) objectivity, (b) subjectivity and (c) practice given in Table 1, structure aspects of scientific brainware can and should be analysed also with reference to ( $\left.a^{\prime}\right)$ objective structure description of the world in a science, $\left(b^{\prime}\right)$ subjective attitudes to make use of the scientific 
brainware, and $\left(c^{\prime}\right)$ practical procedures to manage the scientific brainware. It is worth while to notice that three categories of science, called (i) discipline-oriented science, (ii) mission-oriented sciences, and (iii) assessment-oriented sciences should be taken in our consideration in order that we may be able to have a unified viewpoint to deal with $\left(a^{\prime}\right),\left(b^{\prime}\right)$ and $\left(c^{\prime}\right)$. Discipline-oriented sciences are mainly concerned with $\left(a^{\prime}\right)$, while mission-oriented sciences can not be satisfied without dealing with $\left(b^{\prime}\right)$ as well. Now the problem of providing $\left(a^{\prime}\right)$ objective description of the world in a science has the common philosophical aspects besides the specific features characteristic in the sperific science. Regarding the former aspects we have discussed in our previous paper [1] the notion of world structure description in a broad sense. In the context of the present section, it is necessary and sufficient to refer to the following three categories of description: (A) existence description, (B) interrelation description, and (D) motion description, without reference to (D) feasibility description.

Each of these three description categories ought to be interpretated in an abstract way, since they are intended to provide a vast coverage over all the basic notions in the different discipline-oriented sciences, as can be observed from the breakdowns of each of these description categories into their respective subcategories:

A. Existence description: A-1 Matter; A-2 Energy; A-3 Information.

B. Interrelation descriptions: B-1 Connection; B-2 Independence; B-3 Conflict.

C. Motion description: C-1 Statics; C-2 Dynamics ; C-3 Evolution ; C-4 History (including Revolution).

We are not intending to discuss in any more detail the implications of each of these categories and their respective breakdowns, but in stead our attention will be concentrated to any possible correspondence to be traced among the objectivity aspects (a) of informative logics in Table 1 and the world structure descriptions given just now.

Then it will not take much time to realise that $\left(a_{1}\right)$ pattern, $\left(a_{2}\right)$ chaos, and $\left(a_{3}\right)$ transformation in the objectivity aspects (a) of informative logics correspond to (B) interrelation, (A) existence, and (C) motion respectively when each of these fuzzy notions will have been adequately interpretated in virtue of relativistic logics of mutual specifications given in [8].

After getting these correspondences we can now turn to a mathematical formulation through which these correspondences can be interpretated. In fact here we can propose to introduce a graph theoretical formulation which is cur-

Table 2. Structure correspondences among three objective structure descriptions (OSD)

\begin{tabular}{l|c|c|c}
\hline $\begin{array}{c}\text { Objective structure } \\
\text { descriptions (OSD) }\end{array}$ & Control & Eizon & Creation \\
\hline OSD in science & . B) interrelation & $(\mathrm{A})$ existence & $(\mathrm{C})$ motion \\
OSD in informative logics & $\left(\mathrm{a}_{1}\right)$ pattern & $\left(\mathrm{a}_{2}\right)$ chaos & $\left(\mathrm{a}_{3}\right)$ transformation \\
OSD in graph theory & $\left(\mathrm{g}_{1}\right)$ chord & $\left(\mathrm{g}_{2}\right)$ node & ( $\left.\mathrm{g}_{3}\right)$ route \\
\hline
\end{tabular}


rently adopted for data model description. In this way we have a sequence of reduction procedures starting from objective structure descriptions (OSD) in science to graph theoretical formulations through the channel of informative logics, as shown in the following Table 2.

$\left(2^{\circ}\right)$ Structure formation methodologies

A crucial aspect of structure formation of scientific brainware will occur in the situations where a new input information, which is duly acquired, is subject to a comparison with the existing structure description of a science.

Here the comparison implies the testing whether either one of the new input information and the existing structure description should be rejected or the former can be accepted within the framework of the latter.

In this connection it should be pointed out that not a few works have been given in the area of successive precesses of statistical inferences and controls which deserve to the specific attentions of the research workers in dealing with the present problem.

(i) Data analysis is indispensable in information processing for structure formation procedures including acquisition, reduction and evaluation, as can be observed in Tukey [9], Kitagawa [10], [11].

(ii) A relativistic logic of mutual specification developed in Kitagawa [8] is crucially important in dealing with input information whose source may come from field surveys and uncontrolled observations, where our analysis can start with testing hypothesis under a prescribed structure.

(iii) Nets of statistical inferences in various types of successive pooling of data were proposed by Kitagawa [8] in the realm of relativistic logics of mutual specifications in statistics. Now it ought to be remarked that various types of successive pooling of data will be useful to structure formation procedures of scientific brainware in which the comparison between each acquired new input information and the existing structure of the brainware is always open to a serious question and in which various procedures of successive poolings may be adopted according to the informative structural stability degree of the existing structure of the brainware.

It is remarked here that these methodologies of structure formation to be used in building up scientific brainware come from our own researches on successive processes of statistical inferences [12], [13], as explained in our recent paper [14].

\section{References}

[1] Kitagawa, T.: Brainware concept in intelligent and integrated information system, Research Institute of Fund. Information Science, Kyushu Univ., Research Report No. 39 (1974), 1-20: presented to the FID/RI Committee "Research on the Theoretical Basis on Informa. tion", Meeting on "Information Science, its scope, objects of research and problems" in Moscow, 1974, April 24-26.

[ 2 ] Kitagawa, T: The Logic of Information Science (In Japanese), Tokyo, Kodansha, Contemporary Series, Vol. 200 (1969).

[ 3 ] KITAGAwA, T.: There coordinate systems for information science approaches, Information 
Sciences, 5 (1973), 157-169.

[4] Kitagawa, T.: The role of information science in the unification of sciences, Research Institute of Fund. Information Science, Kyushu Univ., Research Report No. 48 (1974), 1-35.

[5] Kitagawa, T.: Fuzziness in informative logics, Fuzzy sets and their applications to cognitive and decision processes (ed. by Zadeh. A, Tanaka, K \& others), Acad. Press., 1975, 97-124.

[6] Kitagawa, T.: The future aspect of quality control in cybernetical era, Proc. of the International Conference of Quality Control, Tokyo, 1969 IS. 14-01, 857-860.

[ 7 ] KITAGAWA, T.: The logic of iuformation sciences, and its implications for control processes in large systems, The Second "FORMATOR" Symposium on Mathematical Methods for the Analysis of Large-Scale Systems, Pragne. (1974), 13-31.

[8] Kitagawa, T.: The relativistic logic of mutual specification in statistics, Mem. Fac. Sci. Kyushu Univ., Ser. A, 17 (1963), 76-105.

[ 9 ] Tukey, J.: The future of data analysis, Ann. Math. Statist., 33 (1962), 1-67.

[10] Kitagawa, T.: Automatically controlled sequence of statistical procedure in data analysis, Mem. Fac. Sci. Kyushu Univ., Ser. A, 17 (1963), 106-139.

[11] Kitagawa, T.: Automatically controlled sequence of statistical procedures, Bernoulli, Bayes, Laplace, Anniversary Volume, Berlin, Springer-Verlag (1965), 146-178.

[12] Kitagawa, T.: Successive process of statistical inferences, Mem. Fac. Sci. Kyushu Univ., Ser. A, 5 (1950), 139-180; 6 (1951), 54-95; 6 (1952), 131-155; 7 (1953), 81-105; 8 (1953), 1-29; Bull. Math. Statist., 5 (1951), 35-50.

[13] KitagAwA, T.: The logical aspects of successive processes of statistical inferences and controls, Bull. Inst. Intern. Statist., 38 (1961), 151-164.

[14] Kitagawa, T.: Statistics and brainware in intelligent and integrated information system, Research Institute of Fund. Information Science, Kyushu Univ., Research Report No. 58 (1975), 1-13: presented to the 40th Session of International Statistical Institute, held in Warsaw, September 1-9, 1975. 